\title{
Employee Intention to Stay in Colombo Based Information Technology Industry: An Investigation on The Impact of Employee Retention Factors
}

\author{
K.D.H.N. Binushika ${ }^{1} \&$ T.K. Karandakatiya ${ }^{2}$ \\ 1,2 Department of Business Management \\ Faculty of Business Studies \& Finance \\ Wayamba University of Sri Lanka \\ Kuliyapitiya \\ SRI LANKA \\ naduni.hewage@outlook.com¹, thusithakk@gmail.com²
}

\begin{abstract}
Employee Retention is considered to be a major concern any industry where the employee turnover rate tends to be higher. When it comes to the Information Technology (IT) industry (where in Sri Lanka or at global level), there is a visible trend in the employee turnover when compared to the other industries. More specifically, the employee turnover of IT industry employ has been identified as a crucial issue in the Asian context including Sri Lanka. The main purpose of this paper is to identify the impact of some selected employee retention factors on employees' intention to stay within the IT companies of the Colombo Suburbs, Sri Lanka. A model was designed and the hypotheses were empirically tested from data collected through a survey. Correlation and multiple regression analysis were carried out to test the association and the degree of impact of the selected employee retention factors on Employees' intention to stay. The analysis results indicated that all the three independent variables (Employee Career Progression, Organizational Culture, and Flexible Working Hours) are positively associated with the dependent variable. The findings of this research also indicate that, career progression and flexible working hours has a high degree of impact on employees' intention to stay where the organizational culture has only a negligible impact on the employees' intention to stay. The research results will have implications for any IT organization operating within the Colombo Suburbs. This research also opens up new opportunities for academicians in studying cross-linkages among the various key factors identified by the study.
\end{abstract}

Keywords:- Employee intention to stay, Key retention factors, IT firms, Colombo suburbs.

\section{INTRODUCTION}

Effective employee retention is a systematic effort made by employers to create and foster an environment that encourages employees to remain employed in the current organization. Employee retention helps have satisfied employees, to increase sales and to preserve the best knowledge base within the company. The 
outburst of the concept of employee turnover which is also known as the lack of employee's intention to stay, has created a new perspective for the companies especially in the IT industry to search for new and better ways to retain their best talent without letting them go into the hands of the rivals.

The present study mainly focusses on the IT industry where one of the major drivers of global IT industry is identified as the technically skilled staff. Sri Lanka's ICT workforce has grown by 42,019 employees since the last project of 82,854 in 2014 to reach 124,873 in 2018. This implies $50.7 \%$ growth during the period concerned at Compound Annual Growth Rate (CAGR) of $10.8 \%$ (LBO, 2019). Even though there is a significant growth in the IT workforce, it is also really challenging to retain the staff. Therefore, it is evident that Employee Turnover is one of the most common problems in the IT industry. Due to the high amounts of employee turnover in various contexts (Global, Asian and Local), the employee retention has become a real challenge. The global IT industry employee turnover counts up to $13.2 \%$ and there is also a constant growth in the annual turnover rate globally. Nearly $50 \%$ of the employees leaving the job are leaving for jobs in the same industry for better packages and benefits. As an average, the IT industry employee turnover rate from 2013 to 2018 is at 23\%(Florentine, 2019).

Same as the global context, there is a significant increase in the turnover rates in most of the Asian countries too. The turnover rates in main Asian markets can be listed as; India $13.6 \%$, Malaysia $13.0 \%$, Australia 12.4\%, Singapore $11.7 \%$, Hong Kong at $11.3 \%$ and China at $10.8 \%$ (Asia One, 2017). It is also observable that job-hopping has become the new attitude of Asian employees. This is also supported by the number of years' employees these days stick with one company which is 2-5 years (Getzoff, 2020).

The problem then triggers down to Sri Lankan context too.ICT workforce in Sri Lanka is currently undergoing deep structural changes and the future growth of the ICT sector is highly dependant on the availability of a skilled workforce (ICTA, 2019). Employee Turnover in the Sri Lankan IT industry shows a growing trend from past, where overall employee turnover of IT workforce has been doubled from $6.6 \%$ in 2004 to $13 \%$ in 2006 (ICTA, 2019). To be more specific, this problem mainly exists in the Colombo suburbs. The main reason for the researcher to choose the Colombo suburbs was because, most of the IT-related companies are situated in Colombo. Where Colombo was ranked among "Top 20 emerging cities"(Wikipedia, n.d.). This is because the industry is rapidly progressing towards a quality destination where most of the recent developments of ICT firms such as, Virtusa (Orion City- Dematagoda), WSO2 (Colpety- Colombo), Millenium IT (Malabe- Colombo), Pearson Lanka and Wiley (Maga one - Nawala) are mainly established in Colombo(SLASSCOM, 2014).From the existing evidence, it was also 
clear that the problem of Employee Turnover was mainly in the middle level employees, where most of the people were having a tenure for about 5- 7 years in the current organization and had emerging family responsibilities. The main drawbacks of employee turnover in the IT industry were the loss of knowledge to the company, training and development cost and the damage for the employer brand image.

Certain measures like induction programs, free online resources were taken to minimize the Employee Turnover and to improve Employee Retention. But all of them have not always given successful results. Also, the studies done within the Sri Lankan context is very limited and there is still a clear gap for extensive studies.

Therefore, there is no sufficient knowledge on the impact of the employee retention factors (Organizational Culture, Employee Career Progression and Flexible Working Hours) on the Employees' Intention to stay in the IT companies in Colombo Suburbs.

In order to address the said problem and to bridge the gap of knowledge, the following research objectives were developed.

1. To investigate whether the factors of employee retention (Organizational Culture, Flexible work hours and Career growth) affect the employees' intention to stay of the middle level employees in IT industry in Colombo suburbs.

2. To identify the degree of impact of employee retention factors (Organizational Culture, Flexible work hours and Career growth) on employees' intention to stay of the middle level employees in IT industry in Colombo suburbs.

In order achieve these objectives; the researcher developed a conceptual framework and hypotheses with the support of existing literature.

It is proven that retention factors (Opportunity for growth, job security and other rewards etc.) have a direct relationship with job satisfaction and therefore, once the employee is satisfied with the job, there is a high tendency to have an intention to stay with the current employer (Das \& Baruah, 2013). When taking each independent variable and its relationship with the dependent variable, there are plenty of comparable studies which have focused on them. Organizational culture has been identified as a high impacting factor for employee retention and employees' intention to stay than the factors of continuous commitment and normative commitment (J, N, \& Begum, 2016).Person- Culture fit is related to employee commitment and satisfaction which results in employee's intention to retain in an organization(O'Reilly, Chatman, \& Caldwell, 1991). Career development has been identified as the top reason for retention and have also proven 
that there is an impact of employee career development in order for an employee to retain or leave an organization (Graham, 2017). In certain studies, it was founded out that the flexible working hours has a significant and a strong impact on employees' intention to stay in an organization(Sloan Center on Aging \& Work at Boston College) . In 2013, Lahkar and Baruah stated that the main retention factors affecting employees' intention to stay in an IT Organization in the Colombo Suburbs are career planning and development, Flexible working hours, working conditions with leadership and supervision. There is also an empirical link between training and development, career development, compensation and performance appraisal and employees' intention to stay(Johanim, Yean, Adnan, \& Yahya, 2012). Most of these studies are done in other countries of the world as stated above, and a very little amount of emphasis have drawn towards this area in Sri Lankan context. Therefore, there is a clear knowledge gap in this area specifically in the Sri Lankan context.

After an extensive review on existing literature, a conceptual model was developed to theorize and to show the logical sense of the relationship among the several factors that have been identified as important to the problem. From theoretical framework researcher identified that the independent variables of organizational culture, employee career progression and flexibility of working where Employees' intention to stay was identified as the dependent variable in the study.

\section{METHODS}

The present research is consisting of both correlational study and a causal study. This is identified as a correlational study simply because, the study attempts to identify the association of the employee retention factors and employees' intention to stay. At the same time, it is a causal study because, it attempts to establish a cause and effect relationship.

The population considered in this study is mainly the middle level employees of the top three IT firms in Colombo Suburbs, Sri Lanka. The researcher personally consulted each company to develop the sample frame. With the total population of 1580 employees, the researcher founded it difficult to conduct the study for the entire population. Therefore, a reliable and a valid sample of 307 middle level IT employees from three designated IT companies in the Colombo suburbs, was selected using the Morgan's table. The researcher has used the simple random sampling method which falls under the category of probability sampling where the selection of sampling units based on being randomly selectable and assessable by the researcher. Here, there is possibility for each and every element in the population to get a chance to get selected to the sample. For this study, the researcher would consider that all the respondents have uniform characteristics and have no any changes based on their perspectives for the study under consideration.

Established dimensions and instruments were used in order to 
measure the independent variables of Organizational culture (OC) (Sheridan, 1992), Employee Career Progression (CP) (Gyanash \& Guntai, 2018), Flexible Working Hours (FW) and the dependent variable of Employees' intention to stay (IS) (Johari, Yean, Adnan, Yahya, \& Ahmad, 2012). Thus, it was considered to be the most suitable for the purpose of the study. As major dimensions of the dependent variable employees' intention to stay, can be stated as the Working hours, Satisfaction with the current job, etc. Similarly, the dimensions of the selected employee retention factors which include the Organizational culture can be identified as innovations, relationships, etc. The main dimensions of the Employee career progression are identified as the career path, promotion and professional ability development. In order to measure the Flexible working hours, the significant dimensions used are the shift, work schedule and rest time.

In order to collect the primary data required for the study, a structured questionnaire was distributed. The study collected data from IT industry employees through a questionnaire to find out, to what extent retention factors (Organizational culture, employee career progression and flexible working hours) impact on employees' intention to stay. So beyond distributing a questionnaire the researcher didn't interfere with the normal activities. The research was conducted in a natural environment with a minimum interference of the researcher with the normal flow of work.
The questionnaire consisted of two sections where one section collected the demographic information of the respondents and the second section was used to gather ideas about the selected employee retention factors and employees' intention to stay. The part two of the questionnaire were prepared on five points Likert scale and the questionnaire was developed in English Language. In order to collect the data, a set of questionnaires were given to the $\mathrm{HR}$ department of the three companies A, $\mathrm{B}$ and $\mathrm{C}$ to be presented to the set of selected middle level employees during their HR 101 meetings. The questionnaire was given by hand and collected at that point of time in order to ensure immediate response by the respondents and to secure the employee responses given. Even though the sample size was 307 employees, 350 questionnaires were distributed, considering the nonresponse rate in Sri Lanka. In order to collect the secondary data, different sources like journals, newspaper articles and government statistical reports were referred.

The basic steps followed in data analysis are; getting data ready for analysis, getting a feel for the data, testing the goodness of data and testing the hypotheses developed. The SPSS software was used in the process of data analysis. However, the respondent profile was analyzed. Initially, to analyze the respondent profile; various descriptive statistical tools such as the range, mean, standard deviation were used. Similarly, in order to have a better visual presentation of the respondent profile, the bar charts were used in 
the study.

Prior to analyzing rest of the data, the researcher ensured that the data is fully ready for the purpose of analyzing. Here, the researcher mainly examined the data and identified any data entry errors, missing values, checked on any extreme or unusual values and finally a test for normality, linearity and multicollinearity was done in order to make sure the data is accurate and ready for an analysis. After ensuring that the data is appropriate for analyzing, the researcher paid more attention towards identifying the validity and reliability of the instruments. For this, the Cronbach's Alpha test was used. As the final step in analyzing the data, the hypothesis and the research model was tested. Accordingly, the researcher checks for the association between the variables by using the correlation analysis and impact of Independent Variables using the multiple regression analysis.

\section{RESULTS}

Number of collected questionnaires was 308, where the sample is only 307. This shows a response rate of $87.7 \%(88 \%)$ for the questionnaire.

The male employees in the sample accounts for $62.5 \%$ while female accounts for $37.5 \%$. The majority of the respondents around $44.95 \%$ were between the age category of 27- 30 years and the minority of $4.89 \%$ were within the age category of 37- 40 years. $35.5 \%$ of the total sample were between the age category of 31- 33 years and only $14.6 \%$ of the total sample were between 34- 36 years of age. The tenure with the current organization was also a significant demographic factor considered when analyzing the characteristics of the sample. The majority with $35.18 \%$ of the total sample had a tenure for more than 7 years with the current organization and a minority of $14.33 \%$ had a tenure in between 2- 3 years in the current organization. There were $24.76 \%$ of employees with a tenure within the current organization between 4- 5 years and $25.73 \%$ accounts for a tenure between 6- 7 years with the current organization. The marital status which is a crucial factor for employees in the IT industry is also considered here. $81.76 \%$ of the total employees were single and only $13 \%$ of the sample were married. There is also a minority of $5.21 \%$ of the total sample who were divorced. The divorced population was also considered as single in this analysis.

Once the demographic data was analyzed, the researcher gave more attention towards making sure that the data set is fully accurate. For this, the researcher has examined the data for any data entry errors, missing values, extreme value using box-plot diagram, normality of the sample using the skewness and kurtosis results, linearity using the $\mathrm{Q}-\mathrm{Q}$ Plots and multicollinearity using the collinearity statistics. After ensuring the data set is accurate, the researcher performed the Cronbach's Alpha test in testing the reliability of the instruments. 
Table 1: Reliability Test

\begin{tabular}{|l|l|}
\hline Construct & $\begin{array}{l}\text { Cronbach's } \\
\text { Alpha }\end{array}$ \\
\hline Career progression & 0.891 \\
\hline Organizational culture & 0.826 \\
\hline Flexible hours & 0.764 \\
\hline Intention to stay & 0.847 \\
\hline
\end{tabular}

Source: Survey Results, 2020

All the variables in each construct shows a higher reliability which is more than 0.6.This claims that all the variables are valid for further analysis. Thus, the internal consistency reliability of the measures used in this study can be considered to be good with the Cronbach's Alpha value of 0.847. In order to find the impact of selected employee retention factors considered in this study on employees' intention to stay, the researcher first focused on finding the association/ relationship between the variables. For this, the researcher used the Pearson Correlation test. Since a specific direction of relationship is not given in the hypotheses, a two tailed test was performed using $5 \%$ of significance level ( $95 \%$ confidence). The Pearson's correlation coefficient value generally ranks from -1 (Strong negative relationship) to +1 (Strong positive relationship). The value indicates both the strength and the direction of the variables under consideration.
Table 2: Correlation of Key Variables

\begin{tabular}{|l|l|c|}
\hline \multicolumn{1}{|c|}{ Construct } & $\begin{array}{c}\text { Correlation } \\
(\mathbf{r})\end{array}$ & $\begin{array}{c}\text { Sig. } \\
(\mathbf{p})\end{array}$ \\
\hline $\begin{array}{l}\text { Career } \\
\text { progression }\end{array}$ & 0.804 & 0.000 \\
\hline $\begin{array}{l}\text { Organizational } \\
\text { culture }\end{array}$ & 0.704 & 0.000 \\
\hline Flexible hours & 0.630 & 0.000 \\
\hline
\end{tabular}

Source: Survey Results, 2020

It is observable that all three constructs have positive coefficients and significant $(p<.05)$. From the results, it is observable that the intention to stay in the current organization is, significantly positively correlated to Organizational Culture, Flexible Working Hours and Employee Career Progression.

Even though there is an obvious association between the dependent variable with the three independent variables, the degree of impact is the another objective of the study. In order to find the degree of impact between the variables and the model significance, a multiple regression analysis was performed.

Table 3: Model Summary

\begin{tabular}{|c|c|c|c|c|}
\hline Model & $\mathbf{R}$ & $\begin{array}{c}\mathbf{R} \\
\text { Squar } \\
\mathbf{e}\end{array}$ & $\begin{array}{c}\text { Adjus } \\
\text { ted R } \\
\text { Squar } \\
\mathbf{e}\end{array}$ & $\begin{array}{c}\text { Std. } \\
\text { Error } \\
\text { of the } \\
\text { Estim } \\
\text { ate }\end{array}$ \\
\hline 1 & $.937^{\mathrm{a}}$ & .878 & .877 & .21570 \\
\hline
\end{tabular}

a. Predictors: (Constant), CP, FW, OC

Source: Survey Results, 2020

2

The Coefficient of determination $\left(\mathrm{R}^{2}\right)$ is used to measure the usefulness/ accuracy of the model. This value always ranges in between $0 \%$ and 
$100 \%$. In general, the higher the coefficient of determination, the better the model fits your data. This shows that the $\mathrm{R}$ squared value of $87.8 \%$ variance of employees' intention to stay explained by all the independent variables. Hence, more variance that is accounted for by the regression model, the closer the data points will fall to the fitted regression line.

Table 4:ANOVA of The Intention to Stay Model

\begin{tabular}{|c|c|c|c|}
\hline Model & $\begin{array}{c}\text { Sum of } \\
\text { Squares }\end{array}$ & F & Sig. \\
\hline $\begin{array}{c}\text { Regressio } \\
\mathrm{n}\end{array}$ & 101.849 & 729.687 & $.000^{\mathrm{b}}$ \\
\hline Residual & 14.097 & & \\
\hline
\end{tabular}

Source: Survey Results, 2020

The ANOVA table is there to show the overall significance of the model. The $F$ value of 729.687 shows the overall significance of the model $(\mathrm{p}<0.05)$.

Table 5: Coefficient Table

\begin{tabular}{|l|c|c|}
\hline \multicolumn{1}{|c|}{ Construct } & \multicolumn{1}{c|}{$\begin{array}{c}\text { Beta } \\
(\mathbf{B})\end{array}$} & $\begin{array}{c}\text { Sig. } \\
(\mathbf{p})\end{array}$ \\
\hline $\begin{array}{l}\text { Career } \\
\text { progression }\end{array}$ & 0.685 & 0.000 \\
\hline $\begin{array}{l}\text { Organizational } \\
\text { culture }\end{array}$ & 0.029 & 0.384 \\
\hline Flexible hours & 0.487 & 0.000 \\
\hline
\end{tabular}

Source: Survey Results, 2020

The coefficients table (table no 5) helps to identify which among the three independent variables influence most and has the higher degree of impact on the dependent variable.
Accordingly, it is observable that employee career progression and flexible working hours had a high degree of impact on employees' intention to stay with $(b=0.685$, $\mathrm{p}<0.05)$ and $(\mathrm{b}=0.487, \quad \mathrm{p}<0.05)$ respectively. In contrary, the Organizational culture hada negligible impact on employees' intention to stay with $(b=0.029$, $\mathrm{p}>0.05$ ).

After performing the analytical tests through SPSS software it can be finally observed in the multiple regression analysis, on which variable has the highest impact on employees' intention to stay. The results showed that as the, employee career progression followed by flexible work hours and organizational culture respectively which is supported by diminishing $\mathrm{B}$ values for each variable.

\section{Multiple Regression Line}

$\mathrm{IS}=-1.351+0.590 \times 1+0.728 \times 2$

The variables of Flexible working hours and Employee career progression are significant because both of their $p<0.05$. The $p$ value of Organizational culture is $\mathrm{p}<0.05 \&$ therefore; the variable is not significant. Therefore, Organizational culture has not been included in the regression equation.

However, test statistics in regression does not support the alternate hypothesis of organizational culture but it supports the alternative hypothesis of flexible working hours and career progression. 
Table 6: Hypotheses Results

\begin{tabular}{|c|c|c|c|}
\hline No. & Independent variable & Dependent variable & $\begin{array}{c}\text { Hypo. } \\
\text { Accepted? }\end{array}$ \\
\hline $\mathrm{H}_{1}$ & Organizational Culture (OC) & Intention to stay & No \\
\hline $\mathrm{H}_{2}$ & Career Progression (CP) & Intention to stay & Yes \\
\hline $\mathrm{H}_{3}$ & Flexible Working Hours (FW) & Intention to stay & Yes \\
\hline
\end{tabular}

Source: Researcher Constructed

\section{DISCUSSION}

Based on the research's results, it can be observed that the Employee career progression \& flexible working hours has a significant influence on employees' intention to stay. Similarly, the previous literature suggested that, a positive relationship between employee career advancement and employees' intention to stay was proved (Wijayawardhana, 2017). In 2019, Wijesiri stated that, when management wants to maintain a good level of employee retention, they should focus more on employee career advancements when formulating policies within the organization (Wijesiri, Sirirwardhana, Thilakarathna, Weerarathna, \& Pathirana, 2019).

The availability of flexible working hours such as flextime and compressed work week seems to help employees experience greater job enrichment which, in turn, is associated with higher job satisfaction and higher intention to stay (McNall, Masuda, \& Nicklin, 2009). The results of the present study also proved that organizational culture doesn't make an impact on employees' intention to stay.
Similarly, in the research of (Haggalla, Lakmini , \& Jayatilake, 2017) have stated that the impact between Organizational Culture always doesn't necessarily need to be a positive impact. However, that should be further researched to make a final conclusion. Accordingly, it is observable that the present study has proved some facts which was also proved by other researchers in their research studies.

From data analysis and discussion, level of effect of each retention factor can be determined. Based on that, to retain employees, the firms can select the suitable strategies under limited resources. The intention to stay of an employee is significantly impacted by employee career progression and flexible working hours. Therefore, to increase employees' intention stay; the key is to increase positive factors and decrease negative factors impacting the employee career progression and Flexible working hours.

In order to increase the employee career progression, the researcher suggest to provide the required L \& D programs in specific areas of soft skill trainings, technical trainings, conferences and certifications. 
Similarly, the researcher also encouraged to provide mentoring and personal coaching sessions and finally to give enough space for the employees to think and be more innovative.

The researcher also recommends the employers to understand about each employee and their preference towards flex- hours. Here one main recommendation provided by the researcher was to allow the employees to effectively work from home and ensure about the quality of work and output rather than the place of work. In order to have a better culture which motivates the employees to retain long in the company, the researcher recommends having an open door policy where even the top local leadership is accessible. It is also recommended to have a uniform culture across all countries where the company operates. The employee onboarding programs must be improved to be more advanced and consistent. The employees must also be given value and recognition throughout their stay. Simple things like giving them the required credit when they achieve something and encouraging words during a failure would go a long way for employees to love their current employee and stay longer with a positive attitude.

\section{CONCLUSION}

The main target of conducting this research was to identify how some selected employee retention factors effect on employees' intention to stay and to what extent each dimension impact on employees' intention to stay in the IT industry in the western province of Sri Lanka. The study concluded that Employee Career Growth have a very strong relationship with Employees' intention to stay while Organizational culture and Flexible working hours had strong and moderate relationships respectively. This proof fulfilled the first objective of the study.

When considering the second objective of the study regarding the degree of impact of retention factors on employees' intention to stay; the employee career progression, flexible working hours and organizational culture can be listed in sequence. The results of this study helps to strengthen the fact that there is an association and a significant impact of employee career progression, flexible working hours and organizational culture on employees' intention to stay. This theoretically contributes to the existing knowledge base in the similar area of study. The practical contribution of this study can be stated as the fact that the researcher mainly focused on a different context for the study. The researcher specifically focused on some selected IT companies in Colombo suburbs, Sri Lanka when conducting the research.

\section{REFERENCES}

Asia One. (2017). With Voluntary Employee Turnover on the Rise, Technology Sector Companies in Singapore and Asia-Pacific Boost 2017 Salary budget.Available at:https://www. asia one. 
com /voluntary-employee-tur no ver-rise-technologysector-compani es singapore-and-asiapacificboost-20 17. (Accessed 9/10/2 020).

Cha,H.S.\&Quan,J.(2011). A Global Perspective on Information Systems Personnel Turnover. Journal of Global Information Technology Management.14(4).

Available at: https://doi.org/10.1080/10971 98X.2011.10856547. (Accessed 9/10/2 020).

Das, B. L., \& Baruah, M. S. (2013). Employee Retention: A Review of Literature. IOSR Journal of Business and Management.14(2).pp.08-16.

Florentine, S. (2019). Employee retention: 8 strategies for retaining top talent. $\mathrm{CIO}$. Available at: https://www.cio.com /article/2868419/how-toimprove-emp loyeeretention.html.(Accessed9/10 / 2020).

Graham, S. (2017). Career Development: A Resource for Talent Retention. [Blog] Cornerstone University. Available at: - learningmatters/ post/career-develo pment-a-resource-for-talentretention (Accessed 20 Aug. 2018).
Gyanash, S., \& Guntai, K. H. (2018). Career Development in Organizations: Placing the Organization and Employee on the same pedestal to enhance maximum productivity. European Journal of Business and Management, 10(14).

Haggalla, K. U., Dr. Lakmini , \& Jayatilake, V. (2017). Study on Organizational Culture and Turnover Intention in International Information Technology Firms In Sri Lanka. International Journal of Scientific Research and Innovative Technology, 4(2).pp.47-63.

ICTA. (2019). National IT - BPM Workforce Survey 2019 Information and Communication Technology Agency of Sri Lanka. Available at: https:/ /www.lankabusinessonline.co $\mathrm{m} /$ icta-launches-national-itbpm-workforce-survey2019/(Accessed 4/5/2020).

J, A., N, F., \& Begum. (2016, January). Role of Organisational Culture and Employee Commitment in Employee Retention. ASBM Journal of Management, 9(1).

Johari, J., Yean, T. F., Adnan, Z., Yahya, K. K., \& Ahmad, M. N. (2012). Promoting Employee Intention to Stay: Do Human Resource Management Practices 
Matter? . Int. Journal of Economics and Management, 6(2). pp.396-416

LBO, 2019. ICTA launches national IT-BPM workforce survey 2019. [Online] Available at: https://www.lankabus inessonline.com/ictalaunches-national -it-bpmworkforce-survey2019/(Acce ssed 30/6/2020).

McNall, L. A., Masuda, A. D., \& Nicklin, J. M. (2009, March 19). Flexible Work Arrangements, Job Satisfaction, and Turnover Intentions: The Mediating Role of Work-to-Family Enrichment. The Journal of Psychology Interdi sciplinary and Applied, 144(1), pp.6181.

Getzoff,M.2020. Most Technologically Advanced Countries in The World 2020. Available at: https://www. gfmag.com/global-data/noneconomic -data/best-techcountries. (Accessed9/ 10/2020).

O'Reilly, C. A., Chatman, J. A., \& Caldwell, D. F. (1991, September). People and Organizational Culture: A Profile Comparison Approach to Assessing Person-Organization Fit. The Academy of Management Journal.34(3).pp.487-516.
Sheridan, J. E. (1992). Organizational Culture and Employee Retention . Academy of Management Journal, 53(5).Available at: https://doi.org/10.5465/2565 39 (Accessed 4/6/2020).

SLASSCOM. (2014). Sri Lankan IT/BPM Industry 2014 Review. Available at: https://slasscom.lk/srilankan-it-bpm-i ndustryreview-2014/(Accessed 5/5/ 2 020).

Sloan Center on Aging \& Work at Boston College. (n.d.). Employers Need - Increase Retention and Reduce Turnover.Available at: https://www. bc.edu/content /dam/files/ research_ sites/ agingandwork /pdf/publications /TMISR02_HealthCare.pdf( Accessed 7/5/2020).

Wijayawardhana, N. (2017, May). Key Factors Affecting for IT Employee Retention: An Empirical Study on Large Scale IT Firms in Sri Lanka.Available at: http://dl.lib.mrt.ac.lk/bitstrea $\mathrm{m} /$ handle/123/13292/pretext. pdf? sequence $=2 \&$ is Allowed $=$ $\mathrm{y}($ Accessed 4/4/2020).

Wijesiri, N., Sirirwardhana, M., Thilakarathna, D., Weerarathna, R., \& Pathirana, U. (2019). Impact of HR Practices on Employee Retention; A Case of BPO Sector, Sri Lanka. 
Binushika K.D.H.N., Karandakatiya T.K., Wayamba Journal of Management 11 (2)

International Journal of Human Resource Studies, 9(1).
Wikipedia. (n.d.). Information Technology in Sri Lanka. Available at: https:// en.. 